\title{
Risk of adverse events with bevacizumab addition to therapy in advanced non-small-cell lung cancer: a meta-analysis of randomized controlled trials
}

This article was published in the following Dove Press journal:

OncoTargets and Therapy

21 April 2016

Number of times this article has been viewed

\section{Xi-Xi Lai \\ Ren-Ai Xu \\ Yu-Ping Li \\ Han Yang}

Department of Respiratory Medicine, The First Affiliated Hospital of Wenzhou Medical University, Wenzhou, Zhejiang, People's Republic of China
Correspondence: Xi-Xi Lai; Han Yang Department of Respiratory Medicine, The First Affiliated Hospital of Wenzhou Medical University, No 2 Fuyi Street, Wenzhou, Zhejiang 32500, People's Republic of China Tel +8657755578166 Email chenlingyan1020@163.com; yanghan20150909@I63.com
Background: Bevacizumab, a monoclonal antibody against vascular endothelial growth factor ligand, has shown survival benefits in the treatment of many types of malignant tumors, including non-small-cell lung cancer (NSCLC). We conducted this systematic review and meta-analysis to investigate the risk of the most clinically relevant adverse events related to bevacizumab in advanced NSCLC.

Methods: Databases from PubMed, Web of Science, and Cochrane Library up to August 2015, were searched to identify relevant studies. We included prospective randomized controlled Phase II/III clinical trials that compared therapy with or without bevacizumab for advanced NSCLC. Summary relative risk (RR) and 95\% confidence intervals were calculated using random effects or fixed effects according to the heterogeneity among included trials.

Results: A total of 3,745 patients from nine clinical trials were included in the meta-analysis. Summary RRs showed a statistically significant bevacizumab-associated increased risk in three of the adverse outcomes studied: proteinuria $(R R=7.55)$, hypertension $(R R=5.34)$, and hemorrhagic events $(\mathrm{RR}=2.61)$. No statistically significant differences were found for gastrointestinal perforation $(P=0.60)$, arterial and venous thromboembolic events $(P=0.35$ and $P=0.92$, respectively), or fatal events $(P=0.29)$.

Conclusion: The addition of bevacizumab to therapy in advanced NSCLC did significantly increase the risk of proteinuria, hypertension, and hemorrhagic events but not arterial/venous thromboembolic events, gastrointestinal perforation, or fatal adverse events.

Keywords: toxicities, angiogenesis inhibitors, non-small-cell lung carcinoma, meta-analysis, safety

\section{Introduction}

Angiogenesis is a key event in the process of cancer growth, invasion, and metastasis. ${ }^{1,2}$ Therefore, inhibition of angiogenesis is regarded as an attractive strategy for cancer treatment. $^{3}$ The vascular endothelial growth factor (VEGF) pathway is well established as one of the key regulators of this process. ${ }^{4}$ Bevacizumab is a recombinant humanized monoclonal antibody that binds to the VEGF-A ligand and prevents it from binding to its receptors. Currently, bevacizumab has been approved for the treatment of many types of solid tumors, including non-small-cell lung cancer (NSCLC), ${ }^{5,6}$ colorectal cancer, ${ }^{7,8}$ renal cell carcinoma, ${ }^{9,10}$ ovarian cancer, ${ }^{11,12}$ cervical cancer, ${ }^{13}$ and so on. Therefore, the use of bevacizumab is expected to increase in the near future, and it would be useful for clinicians to clearly know the severe adverse events (AEs) related to bevacizumab therapy in the treatment of advanced NSCLC.

Generally, bevacizumab has been regarded as well tolerated. However, bevacizumab presents an anti-VEGF toxicity profile with the most common AEs being 
hypertension, ${ }^{14-16}$ proteinuria, ${ }^{14,17}$ and hemorrhagic events. ${ }^{18,19}$ Although several meta-analyses have been conducted to assess the risk of anti-VEGF toxicities associated with bevacizumab, most of these studies include different tumor types. ${ }^{14,15,18,19}$ It has been reported that some tumordependent intrinsic mechanisms have been related to AEs and patient baseline characteristics differ between tumor types. Additionally, time-to-treatment failure and follow-up duration vary according to tumor types, and these factors are closely related to the likelihood of developing and detecting AEs. As a result, the risk of bevacizumab-related toxicities might vary among tumor types. In fact, significant heterogeneity is found when pooled risk data are studied by tumor types in the recent several meta-analyses. For example, it had been found that the risk of bevacizumabrelated hypertension, ${ }^{14}$ gastrointestinal (GI) perforation, ${ }^{20}$ and arterial thromboembolic events (ATEs)/venous thromboembolic events (VTEs) ${ }^{21,22}$ significantly varied with tumor types. Thus, the risk of bevacizumab-associated toxicities in advanced NSCLC remains unknown. Therefore, we conduct this comprehensive meta-analysis of randomized controlled trials to assess the overall risk of severe AEs related to bevacizumab in the treatment of advanced NSCLC.

\section{Methods}

\section{Data sources}

\section{Selection of studies}

The Cochrane Central Register of Controlled Trials (CENTRAL), PubMed (up to August 2015), and Web of Science (up to August 2015) databases were searched for articles using "bevacizumab", “avastin”, "non-small-cell lung cancer", "prospective", "phase II/III", "randomized controlled trial", and "humans". We also searched abstracts and virtual meeting presentations from the American Society of Clinical Oncology (http://www.asco.org/ASCO) conferences that took place between January 2004 and January 2014. Each publication was reviewed, and in cases of duplicate publication, only the most complete, recent, and updated report of the clinical trial was included in the meta-analysis.

To assess the relationship between the use of bevacizumab and clinically significant AEs, we studied AEs classified as grade $\geq 3$ by the National Cancer Institute - Common Toxicity Criteria. ${ }^{23}$ To be included in the meta-analysis, a study had to satisfy the following requirements: 1) prospective randomized controlled trial of patients with advanced NSCLC; 2) participants assigned to treatment with or without bevacizumab in addition to concurrent chemotherapy and/or biological agent; and 3) available data regarding adverse outcomes of interest (grade $\geq 3$ AEs of ATEs, VTEs, proteinuria, hypertension, GI perforation, hemorrhagic events, and fatal AEs) and sample size.

\section{Data extraction and clinical end points}

Data extraction and analysis were conducted independently by two independent investigators, and any discrepancy between the reviewers was resolved by consensus according to the Quality of Reporting of Meta-Analyses guidelines. $^{24}$

For each study, the following information was extracted: first author's name, year of publication, trial phase, number of enrolled subjects, treatment arms, number of patients in treatment and controlled groups, median age, median progression-free survival, adverse outcomes of interest (grade $\geq 3$ AEs of ATEs, VTEs, proteinuria, hypertension, GI perforation, hemorrhagic events, and fatal AEs), and dosage of bevacizumab.

\section{Statistical analysis}

To calculate relative risk (RR), patients assigned to bevacizumab were compared only with those assigned to control treatment in the same trial. For one study that reported zero events in the treatment or control arm, we applied the classic half-integer correction to calculate the RR and variance. ${ }^{25}$ For each meta-analysis, the Cochran's Q statistic and $I^{2}$ score were first calculated to determine heterogeneity among the proportions of the included trials. ${ }^{26,27}$ For $P<0.10$ values of the Cochran's Q statistic, the assumption of homogeneity was deemed invalid and a random-effects model was reported. ${ }^{28}$ Otherwise, results from the fixed-effects model were reported. Finally, potential publication biases were evaluated for severe AEs using Begg's and Egger's tests. ${ }^{29}$ A two-tailed $P$-value of $<0.05$ without adjustment for multiplicity was considered statistically significant. The results of the meta-analysis were reported as classic forest plots. The Jadad scale was used to assess the quality of included trials based on the reporting of the studied methods and results. All statistical analyses were performed by using Version 2 of the Comprehensive Meta-Analysis program (Biostat, Englewood, NJ, USA).

\section{Results \\ Search results}

A total of 213 studies were identified from the database search, of which 71 reports were retrieved for full-text evaluation. Nine trials met the inclusion criteria and were included in this systematic review for analysis (Figure 1). ${ }^{5,6,30-36}$ Table 1 


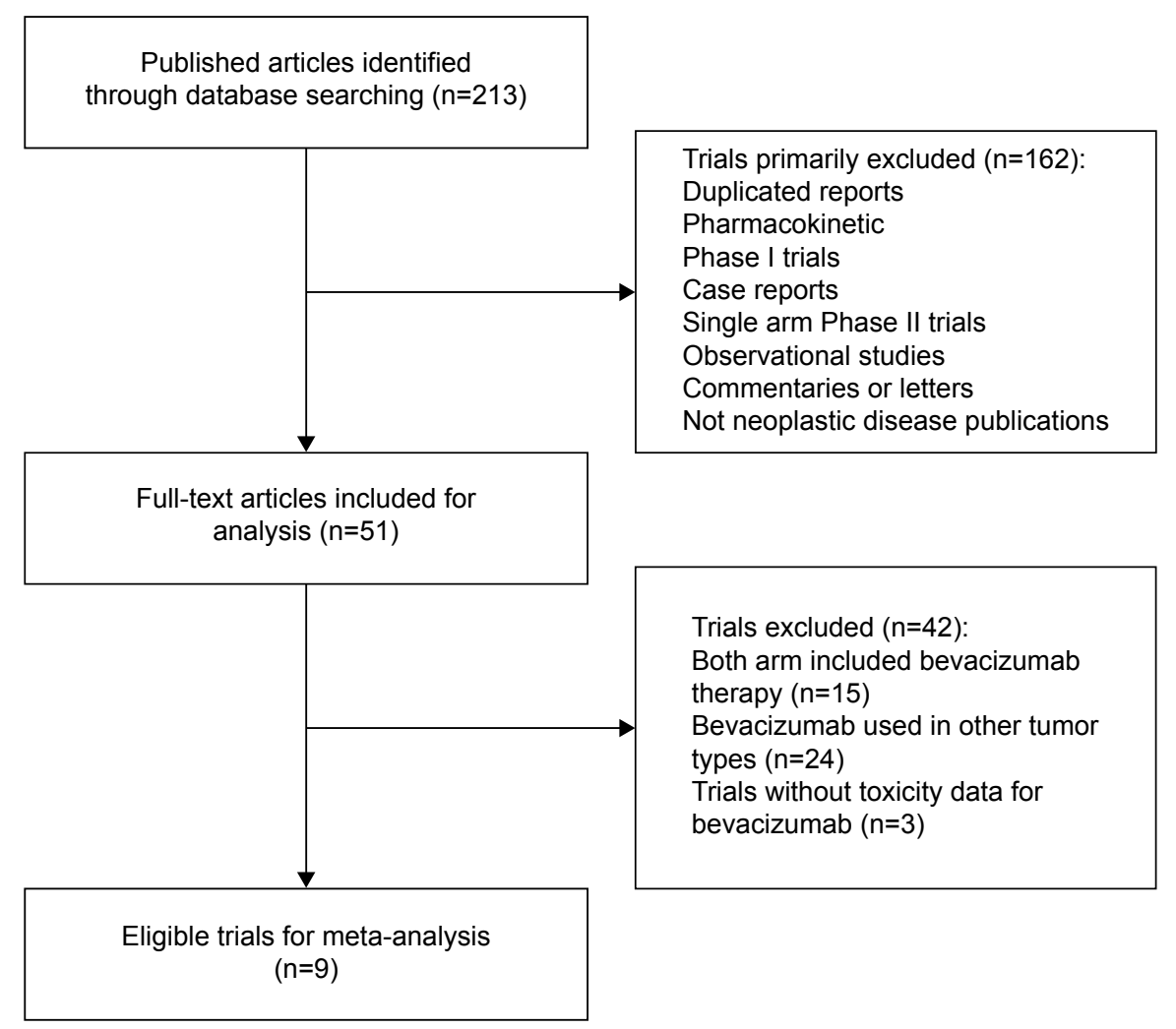

Figure I Studies eligible for inclusion in the meta-analysis.

Table I Baseline characteristics of nine trials included for analysis

\begin{tabular}{|c|c|c|c|c|c|c|c|}
\hline $\begin{array}{l}\text { Name of } \\
\text { clinical trial }\end{array}$ & Authorlyear & Phase & $\begin{array}{l}\text { Line of } \\
\text { treatment }\end{array}$ & $\begin{array}{l}\text { No of } \\
\text { patients }\end{array}$ & Treatment regimens & $\begin{array}{l}\text { Median } \\
\text { age, } y\end{array}$ & $\begin{array}{l}\text { Median } \\
\text { PFS, } \mathrm{m}\end{array}$ \\
\hline \multirow[t]{3}{*}{ NR } & Johnson et al/2004 & II & First line & 99 & Bevacizumab $2.5 \mathrm{mg} / \mathrm{kg} / \mathrm{wk}+\mathrm{PTX}+\mathrm{CBP}$ & NR & 4.3 \\
\hline & & & & & Bevacizumab $5 \mathrm{mg} / \mathrm{kg} / \mathrm{wk}+\mathrm{PTX}+\mathrm{CBP}$ & NR & 7.4 \\
\hline & & & & & $\mathrm{PTX}+\mathrm{CBP}$ & NR & 4.2 \\
\hline \multirow[t]{2}{*}{ NR } & Sandler et al/2006 & III & First line & 878 & Bevacizumab $5 \mathrm{mg} / \mathrm{kg} / \mathrm{wk}+\mathrm{PTX}+\mathrm{CBP}$ & NR & 6.2 \\
\hline & & & & & $\mathrm{PTX}+\mathrm{CBP}$ & NR & 4.5 \\
\hline \multirow[t]{3}{*}{ AVAil } & Reck et al/2009 & III & First line & $\mathrm{I}, 043$ & Bevacizumab $5 \mathrm{mg} / \mathrm{kg} / \mathrm{wk}+\mathrm{GEM}+\mathrm{DDP}$ & 59 & 6.7 \\
\hline & & & & & Bevacizumab $2.5 \mathrm{mg} / \mathrm{kg} / \mathrm{wk}+\mathrm{GEM}+\mathrm{DDP}$ & 57 & 6.5 \\
\hline & & & & & Placebo + GEM + DDP & 59 & 6.1 \\
\hline \multirow[t]{2}{*}{$\mathrm{BeTa}$} & Herbst et al/20II & III & Second line & 636 & Bevacizumab $5 \mathrm{mg} / \mathrm{kg} / \mathrm{wk}+$ erlotinib & 64.8 & 3.4 \\
\hline & & & & & Placebo + erlotinib & 65 & 1.7 \\
\hline \multirow[t]{2}{*}{ JOI9907 } & Niho et al/2012 & $\|$ & First line & 180 & Bevacizumab $5 \mathrm{mg} / \mathrm{kg} / \mathrm{wk}+\mathrm{PTX}+\mathrm{CBP}$ & 61 & 6.9 \\
\hline & & & & & $\mathrm{PTX}+\mathrm{CBP}$ & 60 & 5.9 \\
\hline \multirow[t]{2}{*}{ JO25567 } & Seto et $\mathrm{al} / 2014$ & II & First line & 154 & Bevacizumab $5 \mathrm{mg} / \mathrm{kg} / \mathrm{wk}+$ erlotinib & 67 & 16 \\
\hline & & & & & Placebo + erlotinib & 67 & 9.7 \\
\hline \multirow[t]{2}{*}{ ERACLE } & Galetta et al/20I5 & III & First line & 118 & $\begin{array}{l}\text { Bevacizumab } 5 \mathrm{mg} / \mathrm{kg} / \mathrm{wk}+\mathrm{PEM}+\mathrm{DDP} \\
\text { maintenance with bevacizumab }\end{array}$ & 62 & 8.3 \\
\hline & & & & & PEM + DDP maintenance with PEM & 60 & 8.1 \\
\hline \multirow[t]{2}{*}{ BEYOND } & Zhou et al/20I5 & III & First line & 276 & Bevacizumab $5 \mathrm{mg} / \mathrm{kg} / \mathrm{wk}+\mathrm{PTX}+\mathrm{CBP}$ & 57 & 9.2 \\
\hline & & & & & $\mathrm{PTX}+\mathrm{CBP}$ & 56 & 6.5 \\
\hline \multirow[t]{2}{*}{ PRONOUNCE } & Zinner et al/20I5 & III & First line & 361 & $\begin{array}{l}\text { Bevacizumab } 5 \mathrm{mg} / \mathrm{kg} / \mathrm{wk}+\mathrm{PEM}+\mathrm{DDP} \\
\text { maintenance with bevacizumab }\end{array}$ & 65.4 & 5.49 \\
\hline & & & & & PEM + DDP maintenance with PEM & 65.8 & 4.44 \\
\hline
\end{tabular}

Abbreviations: $y$, year; PFS, progression-free survival; $m$, month; NR, not reported; wk, week; PTX, paclitaxel; CBP, carboplatin; GEM, gemcitabine; DDP, cisplatin; PEM, pemetrexed. 
shows the baseline characteristics of the included studies. Overall, a total of 3,745 patients from nine trials were included for analysis. Three trials were double-blinded, randomized, placebo-controlled trials and had a Jadad score of 5. The other six trials had a Jadad score of 3. Table 2 describes the distribution of the number of patients and associated reported AEs in each of the treatment arms for each of the included studies.

\section{Heterogeneity}

No observed heterogeneity for VTEs, GI perforation, hypertension, proteinuria, hemorrhagic events, or fatal AEs was found except for ATEs $\left(I^{2}=78.3 \%, P=0.003\right.$; Table 2$)$. We thus used the random-effects model to pool the risk of ATEs related to bevacizumab.

\section{AEs reported in trials and pooled effects} Arterial and venous thromboembolic events

A total of 48 patients with ATEs was reported, 32 (2.6\%) in bevacizumab arms and $16(1.0 \%)$ in control arms. The RR among the included studies ranged from 0.595 to 31.56 . And the pooled results did not find an increased risk of ATEs associated with bevacizumab using a fixed-effects model $(\mathrm{RR}=2.83,95 \%$ confidence interval $[\mathrm{CI}]: 0.32-25.45$, $P=0.35$; Figure 2A).

A total of seven trials reported VTEs data. The pooled incidence of ATEs was $2.60 \%$ among all patients, with 58 $(1.6 \%)$ in bevacizumab arms and $30(1.8 \%)$ in control arms. The pooled RR showed that the use of bevacizumab did not increase the risk of VTEs when compared to controls (RR $=0.98,95 \%$ CI: 0.64-1.51, $P=0.92$ ). Considering vascular events as the sum of total ATEs and VTEs, we also did not observe an increased risk of vascular events related to bevacizumab using a fixed-effects model $(\mathrm{RR}=1.19,95 \%$ CI: 0.47-3.04, $P=0.71$; Figure 2B).

\section{Gl perforation}

Only two trials reported GI perforation data with two (0.3\%) patients in bevacizumab arms, and two $(0.6 \%)$ in control arms. We did not observe increased risk of GI perforation with bevacizumab-containing regimens using a fixed-effects model $(\mathrm{RR}=0.60, P=0.60)$.

\section{Hypertension}

Eight trials reported hypertension data with a total of 184 (5.58\%) patients experiencing grade $\geq 3$ hypertension. The pooled incidence of severe hypertension was more frequent $(8.2 \%)$ in the bevacizumab group than that in the control group (1.7\%). The pooled RR was 5.34 (95\% CI: 3.49-8.16, $P<0.001$ ) using a fixed-effects model (Figure 2C).

\section{Proteinuria}

Six trials reported severe proteinuria with 32 patients in the bevacizumab arms, while no case of proteinuria was observed in the control arm. The pooled RR showed that the use of bevacizumab significantly increased the risk of proteinuria when compared to controls with $\mathrm{RR}=7.55(95 \%$ CI: 2.26-25.22, $P=0.001$; Figure 2D).

\section{Hemorrhagic events}

A total of 89 severe hemorrhagic events $(2.43 \%)$ were reported in the trials, $72(3.6 \%)$ in bevacizumab arms and $17(1.4 \%)$ in control arms. This conferred an overall RR of developing hemorrhagic events of 2.61 (95\% CI: 1.57-4.35, $P<0.001$; Figure 2E).

\section{Grade 5 toxicities}

There was no fatal AE in the JO25567 study. ${ }^{33}$ The ERACLE study reported one grade 5 hemoptysis event in the carboplatin with paclitaxel plus bevacizumab arm, and no grade 5 events were observed in the control arm. The PRONOUNCE

Table 2 Relative risk of adverse outcomes for clinical trials included in the meta-analysis

\begin{tabular}{|c|c|c|c|c|c|c|c|c|}
\hline \multirow{2}{*}{$\begin{array}{l}\text { Adverse outcome } \\
\text { (grade } \geq 3 \text { ) }\end{array}$} & \multirow{2}{*}{$\begin{array}{l}\text { Trials } \\
\text { (n) }\end{array}$} & \multicolumn{2}{|c|}{ No of patients $(n)$} & \multicolumn{2}{|c|}{ Incidence, \% (95\%) } & \multirow[t]{2}{*}{$I^{2}$} & \multirow{2}{*}{$\begin{array}{l}\text { Relative } \\
\text { risk (95\%) }\end{array}$} & \multirow[t]{2}{*}{$P$-value } \\
\hline & & $\begin{array}{l}\text { Bevacizumab, } \\
\text { events/total }\end{array}$ & $\begin{array}{l}\text { Controls, } \\
\text { events/total }\end{array}$ & Bevacizumab & Controls & & & \\
\hline ATEs & 4 & $32 / 1,079$ & $16 / 877$ & $2.6(0.8 \%-7.9 \%)$ & $1.0(0.2 \%-5.6 \%)$ & 78.3 & $2.83(0.32-25.45)$ & 0.35 \\
\hline VTEs & 7 & $58 / 1,919$ & $30 / 1,470$ & $1.6(0.5 \%-4.5 \%)$ & $1.8(0.6 \%-5.6 \%)$ & 14.0 & $0.98(0.64-1.5 I)$ & 0.92 \\
\hline GI perforation & 2 & $2 / 799$ & $2 / 461$ & $0.3(0.1 \%-1.5 \%)$ & $0.6(0.2 \%-1.9 \%)$ & 30.9 & $0.60(0.09-4.10)$ & 0.60 \\
\hline Hypertension & 8 & $162 / 1,870$ & $22 / 1,428$ & $8.2(3.5 \%-17.8 \%)$ & $1.7(0.7 \%-4.2 \%)$ & 0 & $5.34(3.49-8.16)$ & $<0.001$ \\
\hline Proteinuria & 6 & $32 / 1,491$ & $0 / 1,083$ & $2.5(1.2 \%-5.3 \%)$ & 0 & 0 & $7.55(2.26-25.22)$ & 0.001 \\
\hline Hemorrhagic events & 9 & $72 / 2,05$ I & $17 / 1,607$ & $3.6(2.5 \%-5.0 \%)$ & $1.4(0.9 \%-2.2 \%)$ & 0 & $2.61(1.57-4.35)$ & $<0.001$ \\
\hline Fatal adverse events & 8 & $89 / 1,977$ & $51 / 1,530$ & $4.6(3.1 \%-6.7 \%)$ & $2.5(1.2 \%-5.2 \%)$ & 43.9 & $1.21(0.85-1.73)$ & 0.29 \\
\hline
\end{tabular}

Note: $l^{2} \geq 50 \%$ suggests high heterogeneity across studies.

Abbreviations: ATEs, arterial thromboembolic events; VTEs, venous thromboembolic events; Gl, gastrointestinal. 

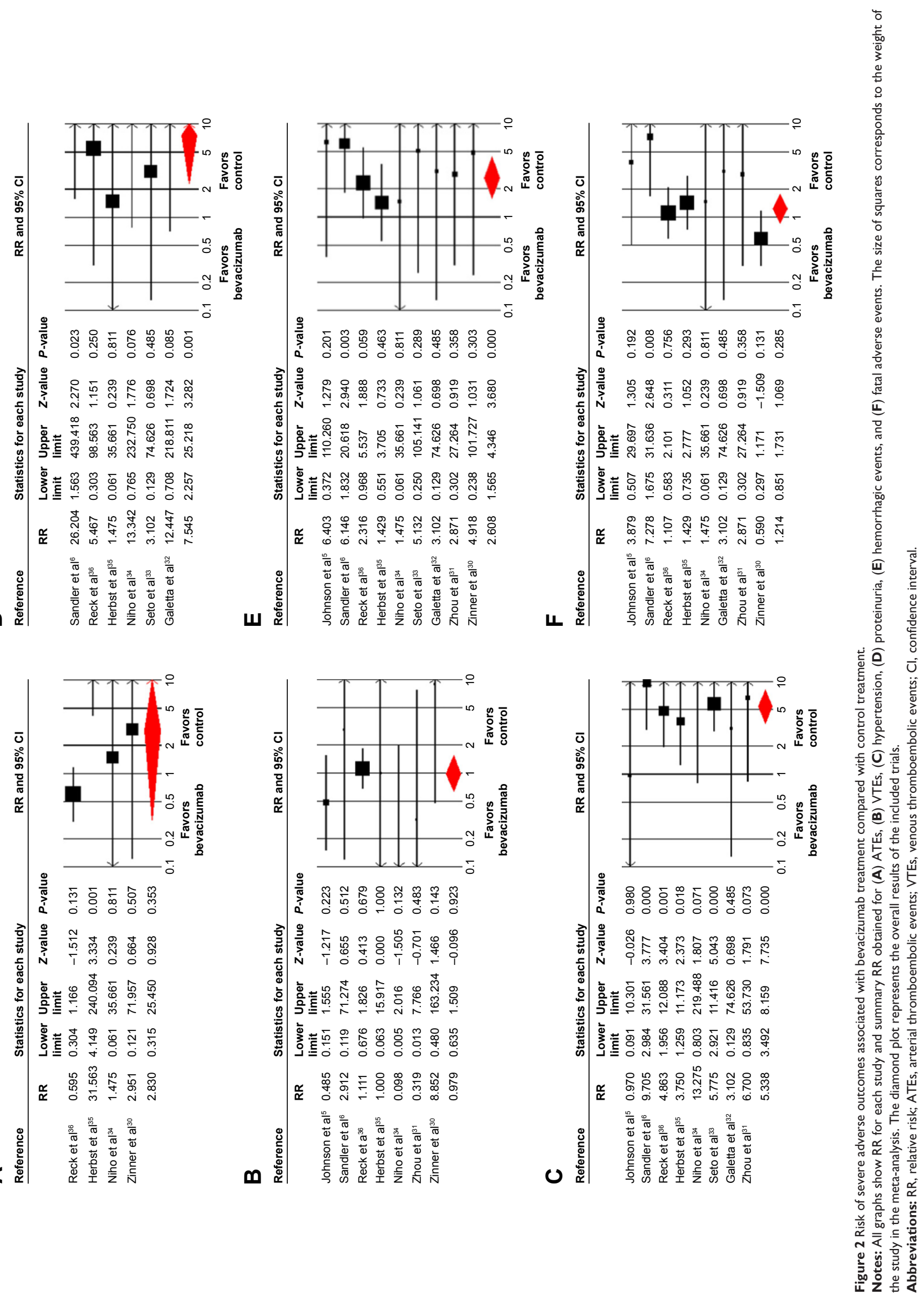
study $^{30}$ reported 12 grade 5 events in the carboplatin with paclitaxel plus bevacizumab arm and 20 grade 5 events in the control arm. The BEYOND study ${ }^{31}$ reported four grade 5 events: three $(2 \%)$ in the carboplatin with paclitaxel plus bevacizumab arm (one event each of cerebral hemorrhage with thrombocytopenia, pulmonary infarction, and cardiac insufficiency) and one grade 5 event in the controlled group (one multiorgan failure).

There were 17 deaths related to toxic effects of the treatment in the study conducted by Sandler et al. ${ }^{6}$ Two deaths (from GI hemorrhage and febrile neutropenia) occurred in patients in the paclitaxel plus carboplatin group and 15 occurred in the paclitaxel plus carboplatin plus bevacizumab group. Of the 15 deaths in the bevacizumab group, five were attributed to pulmonary hemorrhage, five to complications of febrile neutropenia, two each to a cerebrovascular event or GI hemorrhage, and one to a probable pulmonary embolus. The AVAiL study ${ }^{36}$ reported 4\%, 4\%, and 5\% grade 5 events of patients in the placebo, low-dose bevacizumab, and high-dose bevacizumab arms, respectively. In the JO19907 study conducted by Niho et al, ${ }^{34}$ there was one grade 5 hemoptysis event reported in the bevacizumab group and no grade 5 events in the control arm. A total of nine patients died of an AE not directly related to disease progression in the trial conducted by Johnson et al, ${ }^{5}$ four in each of the bevacizumab arms and one in the control arm (sepsis). The causes of death for low-dose bevacizumab included hemorrhage of unknown origin (probable hemoptysis), hemoptysis, unknown cause, and liver failure. In the high-dose arm, the deaths were attributed to aspiration pneumonitis, pulmonary hemorrhage, Aspergillus lung abscess, and chronic obstructive pulmonary disease. The BeTa study ${ }^{35}$ reported $20(6 \%)$ grade 5 AEs in the bevacizumab group, compared with 14 $(4 \%)$ in the control group. Overall, a total of $89(4.6 \%)$ grade 5 AEs were observed in the bevacizumab group and $51(2.5 \%)$ in the control group. This confers a pooled RR of developing grade 5 events of 1.21 (95\% CI: 0.85-1.73, $P=0.29$; Figure $2 \mathrm{~F}$ ).

\section{Publication bias}

No publication bias was detected for the AEs studied except for proteinuria events by either the Begg's or Egger's tests (Begg's test, $P=0.008$; Egger's test, $P=0.012$; Table 3 ).

\section{Discussion}

The angiogenesis pathways, especially the VEGF signal pathway, have been targeted as a therapeutic option. Bevacizumab, a monoclonal antibody that binds to VEGF, is
Table 3 Publication bias: Begg's and Egger's tests ( $P$-value)

\begin{tabular}{lll}
\hline Adverse events & Begg's test & Egger's test \\
\hline ATEs & 0.73 & 0.32 \\
VTEs & 1.0 & 0.75 \\
Gl perforation & 0.90 & 0.13 \\
Hypertension & 0.71 & 0.64 \\
Proteinuria & 0.008 & 0.012 \\
Hemorrhagic event & 0.92 & 0.31 \\
Fatal adverse event & 0.71 & 0.14 \\
\hline
\end{tabular}

Abbreviations: ATEs, arterial thromboembolic events; VTEs, venous thromboembolic events; GI, gastrointestinal.

the only antiangiogenic drug approved for the treatment of NSCLC since it shows overall survival benefit used in combination with chemotherapy. ${ }^{5}$ In contrast with cytotoxic chemotherapy agents, bevacizumab presents an anti-VEGF toxicity profile. ${ }^{37,38}$ However, it has been difficult to assess these toxicities in individual randomized clinical trials due to the limited sample size for analysis. We thus carry out this meta-analysis of nine randomized clinical trials with a total of 3,745 patients to investigate the relationship between those AEs with bevacizumab use. The pooled results show that the addition of bevacizumab to therapy in advanced NSCLC is associated with a significantly increased risk of developing grade $\geq 3$ proteinuria, hypertension, and hemorrhagic events in comparison with controls, while no significant relationship is found between bevacizumab use and risk of fatal AEs, GI perforation, ATEs, or VTEs.

The study of proteinuria events shows the highest RR with 7.55, but this event is rarely clinically significant for NSCLC. Absolute risk and clinical morbidity attributable to proteinuria are low. We also find that the use of bevacizumab significantly increases the risk of severe hypertension and hemorrhagic events, which is consistent with previously published meta-analyses. ${ }^{16,19}$ As we know, severe hypertension including hypertensive crisis may cause significant cardiovascular damage with a possible life-threatening consequence and limit the use of bevacizumab. Therefore, it is particularly important for all clinicians to monitor and treat hypertension or hemorrhagic events in a timely and appropriate manner to prevent long-term complications from toxicities.

Several previous meta-analyses have shown an increased risk of vascular events (ATEs and VTEs) associated with bevacizumab. ${ }^{21,22,39,40}$ However, all of these studies include all tumor types to describe the risk of these AEs, and it is unclear whether the use of bevacizumab would increase the risk of vascular events in patients with NSCLC. For example, in the study conducted by Nalluri et al, ${ }^{22}$ the authors found that the use of bevacizumab was significantly associated 
with an increased risk of developing VTEs, but subgroup analysis according to tumor types showed that there was no significantly increased risk of VTEs in NSCLC, which suggests that the risk of vascular events might be associated with tumor types. In our study focusing on NSCLC, no significant association is found between bevacizumab and risk of vascular events. The meta-analysis conducted by Scappaticci et $\mathrm{al}^{21}$ showed that patients with a prior ATE or age $\geq 65$ years receiving bevacizumab had an increased hazard ratio for ATEs. Baseline characteristics of patients, tumor type, and the sex effect in cardiovascular factors may explain the discrepancy in our finding of no increase in ATEs in patients with NSCLC. Our study do not observe a statistically significant increase in venous thrombotic events with bevacizumab use in NSCLC patients, which is inconsistent with a previously conducted meta-analysis. ${ }^{22}$

We also do not find that the use of bevacizumab is associated with an increased risk of GI perforation $(\mathrm{RR}=0.60$, $P=0.60$ ). GI perforation seems to be less frequent in NSCLC than in other tumor types, suggesting tumor-dependent mechanisms. For example, it is well known that gynecologic cancer commonly have diffused abdominal carcinomatosis, a history of multiple surgeries and radiation exposure, and invasion of the GI tract with tumor cells, which might increase the risk for GI perforation in comparison with patients with NSCLC. ${ }^{20,41}$ Grade 5 adverse outcomes are rare and more frequent in the bevacizumab arm than in the control arm $(4.6 \%$ versus $2.5 \%$, respectively). This could probably be associated with the concomitant treatment with bevacizumab.

Our study has several limitations. First, this is a metaanalysis of published data, and lack of individual patient data prevents us from adjusting the treatment effect according to disease and patient characteristics. Second, meta-analysis is a retrospective research of published studies, thus it is subject to the method deficiencies. For example, baseline proteinuria and hypertension are not mentioned in some included trials. We minimize the likelihood of bias by strictly selecting randomized clinical trials with direct comparison with and without bevacizumab before the analysis. Third, these studies exclude patients with poor renal, hematological, and hepatic functions and were performed mostly at major academic centers and research institutions; the analysis of these studies may not apply to patients with organ dysfunctions and to those present in the community. Finally, as in all meta-analyses, our results may be biased as a result of potential publication bias. However, a funnel plot evaluation for the severe AEs does not indicate publication bias except for proteinuria.

\section{Conclusion}

In conclusion, the addition of bevacizumab to therapy in advanced NSCLC is associated with a statistically increased risk of proteinuria, hypertension, and hemorrhagic events. However, no significantly increased risk of ATEs/VTEs, GI perforation, or fatal AEs is observed in NSCLC receiving bevacizumab-containing regimens. These observations may aid medical oncologists in weighing up the risks and benefits associated with bevacizumab in treating patients with advanced NSCLC.

\section{Disclosure}

The authors report no conflicts of interest in this work.

\section{References}

1. Folkman J. Tumor angiogenesis: therapeutic implications. NEngl JMed. 1971;285(21):1182-1186.

2. Folkman J. Anti-angiogenesis: new concept for therapy of solid tumors. Ann Surg. 1972;175(3):409-416.

3. Folkman J. Role of angiogenesis in tumor growth and metastasis. Semin Oncol. 2002;29(6 suppl 16):15-18.

4. Hicklin DJ, Ellis LM. Role of the vascular endothelial growth factor pathway in tumor growth and angiogenesis. J Clin Oncol. 2005; 23(5):1011-1027.

5. Johnson DH, Fehrenbacher L, Novotny WF, et al. Randomized phase Il trial comparing bevacizumab plus carboplatin and paclitaxel with carboplatin and paclitaxel alone in previously untreated locally advanced or metastatic non-small-cell lung cancer. J Clin Oncol. 2004;22(11): 2184-2191.

6. Sandler A, Gray R, Perry MC, et al. Paclitaxel-carboplatin alone or with bevacizumab for non-small-cell lung cancer. $N$ Engl J Med. 2006; 355(24):2542-2550

7. Kabbinavar F, Hurwitz HI, Fehrenbacher L, et al. Phase II, randomized trial comparing bevacizumab plus fluorouracil (FU)/leucovorin (LV) with $\mathrm{FU} / \mathrm{LV}$ alone in patients with metastatic colorectal cancer. J Clin Oncol. 2003;21(1):60-65.

8. Hurwitz HI, Fehrenbacher L, Hainsworth JD, et al. Bevacizumab in combination with fluorouracil and leucovorin: an active regimen for first-line metastatic colorectal cancer. J Clin Oncol. 2005;23(15): 3502-3508.

9. Yang JC, Haworth L, Sherry RM, et al. A randomized trial of bevacizumab, an anti-vascular endothelial growth factor antibody, for metastatic renal cancer. $N$ Engl J Med. 2003;349(5):427-434.

10. Escudier B, Pluzanska A, Koralewski P, et al. Bevacizumab plus interferon alfa-2a for treatment of metastatic renal cell carcinoma: a randomised, double-blind phase III trial. Lancet. 2007;370(9605): 2103-2111.

11. Burger RA, Brady MF, Bookman MA, et al. Incorporation of bevacizumab in the primary treatment of ovarian cancer. NEngl J Med. 2011; 365(26):2473-2483.

12. Perren TJ, Swart AM, Pfisterer J, et al. A phase 3 trial of bevacizumab in ovarian cancer. $N$ Engl J Med. 2011;365(26):2484-2496.

13. Tewari KS, Sill MW, Long HJ 3rd, et al. Improved survival with bevacizumab in advanced cervical cancer. $N$ Engl J Med. 2014;370(8): 734-743.

14. Zhu X, Wu S, Dahut WL, Parikh CR. Risks of proteinuria and hypertension with bevacizumab, an antibody against vascular endothelial growth factor: systematic review and meta-analysis. Am J Kidney Dis. 2007;49(2):186-193.

15. An MM, Zou Z, Shen $H$, et al. Incidence and risk of significantly raised blood pressure in cancer patients treated with bevacizumab: an updated meta-analysis. Eur J Clin Pharmacol. 2010;66(8):813-821. 
16. Ranpura V, Pulipati B, Chu D, Zhu X, Wu S. Increased risk of highgrade hypertension with bevacizumab in cancer patients: a metaanalysis. Am J Hypertens. 2010;23(5):460-468.

17. Wu S, Kim C, Baer L, Zhu X. Bevacizumab increases risk for severe proteinuria in cancer patients. J Am Soc Nephrol. 2010;21(8): 1381-1389.

18. Hapani S, Sher A, Chu D, Wu S. Increased risk of serious hemorrhage with bevacizumab in cancer patients: a meta-analysis. Oncology. 2010; 79(1-2):27-38.

19. Hang XF, Xu WS, Wang JX, et al. Risk of high-grade bleeding in patients with cancer treated with bevacizumab: a meta-analysis of randomized controlled trials. Eur J Clin Pharmacol. 2011;67(6):613-623.

20. Hapani S, Chu D, Wu S. Risk of gastrointestinal perforation in patients with cancer treated with bevacizumab: a meta-analysis. Lancet Oncol. 2009;10(6):559-568.

21. Scappaticci FA, Skillings JR, Holden SN, et al. Arterial thromboembolic events in patients with metastatic carcinoma treated with chemotherapy and bevacizumab. J Natl Cancer Inst. 2007;99(16):1232-1239.

22. Nalluri SR, Chu D, Keresztes R, Zhu X, Wu S. Risk of venous thromboembolism with the angiogenesis inhibitor bevacizumab in cancer patients: a meta-analysis. JAMA. 2008;300(19):2277-2285.

23. NCI. Cancer Therapy Evaluation Program. CTC v 2.0 and Common Terminology Criteria for Adverse Events Criteria V3.0 (CTCAE). 2013. Available from: http://ctep.cancer.gov/protocolDevelopment/ electronic_applications/ctc.htm. Accessed January 27, 2013.

24. Moher D, Cook DJ, Eastwood S, Olkin I, Rennie D, Stroup DF. Improving the quality of reports of meta-analyses of randomised controlled trials: the QUOROM statement. Quality of reporting of meta-analyses. Lancet. 1999;354(9193):1896-1900.

25. Seng S, Liu Z, Chiu SK, et al. Risk of venous thromboembolism in patients with cancer treated with Cisplatin: a systematic review and meta-analysis. J Clin Oncol. 2012;30(35):4416-4426.

26. Higgins JP, Thompson SG, Deeks JJ, Altman DG. Measuring inconsistency in meta-analyses. BMJ. 2003;327(7414):557-560.

27. Zintzaras E, Ioannidis JP. Heterogeneity testing in meta-analysis of genome searches. Genet Epidemiol. 2005;28(2):123-137.

28. DerSimonian R, Laird N. Meta-analysis in clinical trials revisited. Contemp Clin Trials. 2015;45(pt A):139-145.

29. Egger M, Davey Smith G, Schneider M, Minder C. Bias in meta-analysis detected by a simple, graphical test. BMJ. 1997;315(7109):629-634.

30. Zinner RG, Obasaju CK, Spigel DR, et al. PRONOUNCE: randomized, open-label, phase III study of first-line pemetrexed + carboplatin followed by maintenance pemetrexed versus paclitaxel + carboplatin + bevacizumab followed by maintenance bevacizumab in patients ith advanced nonsquamous non-small-cell lung cancer. J Thorac Oncol. 2015;10(1):134-142.
31. Zhou C, Wu YL, Chen G, et al. BEYOND: a randomized, doubleblind, placebo-controlled, multicenter, phase III study of first-line carboplatin/paclitaxel plus bevacizumab or placebo in Chinese patients with advanced or recurrent nonsquamous non-small-cell lung cancer. J Clin Oncol. 2015;33(19):2197-2204.

32. Galetta D, Cinieri S, Pisconti S, et al. Cisplatin/pemetrexed followed by maintenance pemetrexed versus carboplatin/paclitaxel/bevacizumab followed by maintenance bevacizumab in advanced nonsquamous lung cancer: the GOIM (Gruppo Oncologico Italia Meridionale) ERACLE phase III randomized trial. Clin Lung Cancer. 2015;16(4):262-273.

33. Seto T, Kato T, Nishio M, et al. Erlotinib alone or with bevacizumab as first-line therapy in patients with advanced non-squamous non-smallcell lung cancer harbouring EGFR mutations (JO25567): an open-label, randomised, multicentre, phase 2 study. Lancet Oncol. 2014;15(11): $1236-1244$

34. Niho S, Kunitoh H, Nokihara H, et al. Randomized phase II study of first-line carboplatin-paclitaxel with or without bevacizumab in Japanese patients with advanced non-squamous non-small-cell lung cancer. Lung Cancer. 2012;76(3):362-367.

35. Herbst RS, Ansari R, Bustin F, et al. Efficacy of bevacizumab plus erlotinib versus erlotinib alone in advanced non-small-cell lung cancer after failure of standard first-line chemotherapy (BeTa): a double-blind, placebo-controlled, phase 3 trial. Lancet. 2011; 377(9780):1846-1854.

36. Reck M, von Pawel J, Zatloukal P, et al. Phase III trial of cisplatin plus gemcitabine with either placebo or bevacizumab as first-line therapy for nonsquamous non-small-cell lung cancer: AVAil. J Clin Oncol. 2009; 27(8):1227-1234.

37. Hayman SR, Leung N, Grande JP, Garovic VD. VEGF inhibition, hypertension, and renal toxicity. Curr Oncol Rep. 2012;14(4): 285-294.

38. Klastersky J. Adverse effects of the humanized antibodies used as cancer therapeutics. Curr Opin Oncol. 2006;18(4):316-320.

39. Ranpura V, Hapani S, Chuang J, Wu S. Risk of cardiac ischemia and arterial thromboembolic events with the angiogenesis inhibitor bevacizumab in cancer patients: a meta-analysis of randomized controlled trials. Acta Oncol. 2010;49(3):287-297.

40. Schutz FA, Je Y, Azzi GR, Nguyen PL, Choueiri TK. Bevacizumab increases the risk of arterial ischemia: a large study in cancer patients with a focus on different subgroup outcomes. Ann Oncol. 2011;22(6): 1404-1412.

41. Qi WX, Shen Z, Tang LN, Yao Y. Bevacizumab increases the risk of gastrointestinal perforation in cancer patients: a meta-analysis with a focus on different subgroups. Eur J Clin Pharmacol. 2014;70(8):893-906.
OncoTargets and Therapy

\section{Publish your work in this journal}

OncoTargets and Therapy is an international, peer-reviewed, open access journal focusing on the pathological basis of all cancers, potential targets for therapy and treatment protocols employed to improve the management of cancer patients. The journal also focuses on the impact of management programs and new therapeutic agents and protocols on
Dovepress

patient perspectives such as quality of life, adherence and satisfaction The manuscript management system is completely online and includes a very quick and fair peer-review system, which is all easy to use. Visit http://www.dovepress.com/testimonials.php to read real quotes from published authors. 